\title{
Is Colonic Electrical Activity a Similar Phenomena to Small-Bowel Electrical Activity?
}

\author{
José A. S. Medeiros, M.D., Ph.D., Fausto A. Pontes, M.D., Ph.D., \\ Octávio A. R. O. Mesquita \\ From the Instituto de Fisiologia, Faculdade de Medicina, Universidade de Coimbra, \\ Coimbra Codex, Portugal
}

PURPOSE: This study was designed to investigate colonic spike bursts regarding 1) their migration behavior, 2) their pressure correlates, and 3) comparing colonic short spike bursts with spike bursts from migrating myoelectric complex from the small bowel. METHODS: Rectosigmoid electromyography and manometry were recorded simultaneously in seven normal volunteers and electromyography alone in five others during two hours of fasting and for two hours after one $2,100-\mathrm{kJ}$ meal. One patient with an ileostomy was also studied by the same method to record the migrating myoelectric complex from the terminal ileum during fasting. RESULTS: Three kinds of spike bursts were observed in the pelvic colon: rhythmic short spike bursts, migrating long spike bursts, and nonmigrating long spike bursts. The meal significantly increased the number of migrating and nonmigrating long spike bursts (from 25 to 38.7 percent of the recording time; $P<0.01$ ). These bursts of potentials showed a peak 15 minutes after the meal, which may be caused by the gastrocolic reflex. Migrating long spike bursts started anywhere along the rectosigmoid and migrated from there aborad 82 percent of the time and orad or in both directions in 10 or 7 percent of the time, respectively. They originated pressure waves 99 percent of the time. Short spike bursts were more frequent before the meal ( 15.1 percent before and 9.6 percent after the meal), but the difference was not significant; they neither propagated nor initiated pressure waves detected by the miniballoon. CONCLUSIONS: Migrating long spike bursts were the only potentials that migrated, sometimes for short distances. Short spike bursts are a different phenomenon from the small-bowel migrating myoelectric complex because they do not migrate; they can occur during the postprandial period and never originated intraluminal pressure waves. [Key words: Smooth muscle; Electromyography; Intestinal motility; Motility; Electrophysiology]

Medeiros JAS, Pontes FA, Mesquita OARO. Is colonic electrical activity a similar phenomena to small-bowel electrical activity? Dis Colon Rectum 1997;40:93-99.

$\mathrm{T}$ he interstitial cells of Cajal in the colon, like the ones in the small bowel and other parts of the intestinal tract, probably act as clocks or drivers of

Supported by a grant from the Instituto Nacional de Investigação Cientifica, Proc. DBI-22086.

Presented at the meeting of the Portuguese Congress of Gastrenterology, Vila Moura, Portugal, June 2 to 5, 1993.

Address reprint requests to Dr. Medeiros: Instituto de Fisiologia, Faculdade de Medicina, Universidade de Coimbra, 3049 Coimbra Codex, Portugal. slow waves in the smooth muscle. ${ }^{1}$ Slow waves are oscillatory variations of membrane potential caused by alterations in sodium/calcium/potassium membrane pumps. ${ }^{1-3}$ These slow waves, in the small bowel, set the rhythm of spike bursts, generated on their top, which are known as the migrating myoelectric complex (MMC), minute rhythm, or repetitive bursts of action potentials. ${ }^{4,5}$ These bursts of spike potentials originate phasic contraction waves of the small bowel. Other potentials of the small and large bowels are not dependent on slow waves and seem to be caused by periodic release of the muscle from the tonic influence of nonadrenergic inhibitory nerves in intramural plexuses. ${ }^{6}$ The following are found in the small bowel: migrating action potential complex, potentials associated with giant migrating contractions, and ultrarapid rushes ${ }^{5,7}$; in the colon, migrating long spike bursts (MLSB) and long spike bursts (LSB). ${ }^{8,9} \mathrm{~A}$ type of rhythmic spike potentials, similar in appearance to the spike potentials of MMC, have been described in the colon as short spike bursts (SSB), discrete electrical response activity, and rhythmic spike bursts ${ }^{8-10}$ but seem to have completely different characteristics.

It is generally agreed today that spike potentials, not slow waves, are responsible for contractile activity in the large bowel. However, studies that try to establish a relationship between spike bursts and pressure waves in the large bowel in vivo are scanty and the migration behavior of spike bursts has not been well studied. Also, instrumentation used has varied widely so results are not readily comparable. ${ }^{11}$ Some in vivo studies with electrodes implanted in the serosa were made in the postoperative period. The patients were under surgical stress and were receiving medication $^{12,13}$ that may alter colonic motility for several days. ${ }^{14}$

The introduction by Fleckenstein ${ }^{15}$ and Fioramonti et $a l^{16}$ of intraluminal noninvasive probes for the 
study of myoelectrical activity in the small and the large bowel, respectively, allowed us the possibility of studying human beings under physiologic conditions. With these intraluminal probes, one can obtain the same results as with electrodes implanted in the muscularis, ${ }^{17}$ the mucosa, ${ }^{18}$ or the serosa, ${ }^{12,13}$ although the voltage seems to be shorter. ${ }^{19}$ Miniature balloons seem to be as reliable as open end catheters for pressure recording. ${ }^{20-22}$

The main purpose of this work was 1) to investigate whether short spike bursts in the rectosigmoid are a similar phenomenon as spike bursts of the MMC in the small bowel, namely, whether they migrate, initiate pressure waves, and appear in a cyclic fashion, during fasting, ${ }^{4}$ and 2) to study migration of spike bursts with groups of electrodes close together, because most studies were made with electrodes ten or more $\mathrm{cm}$ apart, and it was conceivable that spike bursts could be originated in any site of the bowel and migrate from there to shorter distances.

\section{MATERIALS AND METHODS}

Twelve volunteers ( 9 men and 3 women) were studied. They had no symptoms of gastrointestinal disease and had normal bowel movements (1-3 formed stools per day). They were not on medication and had never taken laxatives. Ages ranged from 18 to 62 (average, $33.2 \pm 14.1$ ) years (mean \pm standard deviation (SD)). One patient with an ileostomy was also studied by the same method to record the MMC from the terminal ileum during fasting. Seven individuals were studied twice to test reproducibility of the method. Similar results were obtained in both groups.

For this study an electrical probe, similar to the one used by Fioramonti et al., ${ }^{16}$ was built. This probe was made of a polyethylene tube, $10 \mathrm{~mm}$ external diameter and $100 \mathrm{~cm}$ in length. Twenty-eight wires were mounted on the upper $14 \mathrm{~cm}$ of the tube for bipolar recording. Wires were made of insulated nickel/chromium (80 and 20 percent, respectively; Microfil Industries SA, Renens/VD 1-Suisse). Tips of the wires were denuded and rolled up around the upper end of the tube and came out by its lower end. They were attached to a pin plug, which linked the probe to the recorder. A miniature balloon, $0.33 \mathrm{ml}$ in volume, was mounted next to the lowest group of electrodes. A polyethylene catheter, $1 \mathrm{~mm}$ in internal diameter, connected the interior of the balloon to the pressure transducer and the recorder (Fig. 1). A rigid sigmoidoscopy, without any bowel preparation, was per-

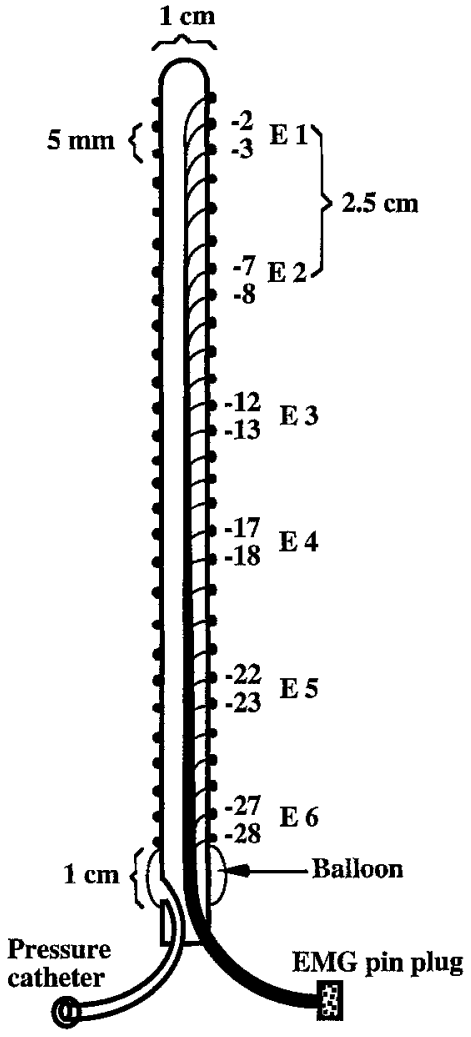

Figure 1. Probe for electromyography (EMG) and pressure recording at the level of $E_{6}$. The wires signaled were used as bipolar electrodes $\left(E_{1}-E_{6}\right)$. Occasionally adjacent wires were used to study migration better. Only spike bursts at $E_{6}$ were correlated with pressure waves in the balloon.

formed for introduction of the probe into the rectosigmoid; it showed no pathology. Contact with the mucosa was adequate because, by increasing the voltage, electrocardiogram artifacts could always be recorded on baseline tracings, when rectosigmoid activity was not present.

An electroencephalograph (Schwartzer 16 channels, Fritz Schwartzer G. M. B. H., Hanover, Germany) was adapted for recording electrical signals. Recordings were made on an eight-channel Hewlett Packard recorder (model 1064C, Type 7758A, Waltham, MA). Six Hewlett Packard medium gain amplifiers 8802A were used for pressure recording. In 7 of 12 patients, intraluminal pressure was recorded simultaneously with electromyography. The first channel of the recorder was used for respiration, the last one for pressure, and the remaining six for electromyography.

A short time constant ( $\mathrm{TC}=0.03$ seconds) was used with no high-pass filters to record only the spike potentials. Slow waves were not studied. Velocity of the recording article was $0.5 \mathrm{~mm} / \mathrm{second}$ most of the time, but higher velocities were used when necessary. 
The electroencephalograph was preset to record potential differences from the following electrode pairs: E1 (2-3), E2 (7-8), E3 (12-13), E4 (17-18), E5 (22-23), and E6 (27-28) $2.5 \mathrm{~cm}$ apart from one another (Fig. 1). Potential differences between any other pairs of adjacent electrodes, which were $0.5 \mathrm{~cm}$ apart, could be recorded by resetting two buttons, thus allowing a more detailed analysis of spike burst migration. Three of the six recording groups of electrodes were positioned in the sigmoid and the other three plus the balloon were positioned in the rectum.

Studies started 30 minutes after introduction of the probe. They were performed during two hours of fasting and for two hours after one $2,100-\mathrm{kJ}$ liquid meal. The meal consisted of Fresubin ${ }^{\mathrm{TM}}$ (Fresenius, LDA, Vila Nova Da Telha, Portugal): $19 \mathrm{~g}$ of protein, $69 \mathrm{~g}$ of carbohydrates, $17 \mathrm{~g}$ of fat, and osmolality of 300 to $350 \mathrm{mOsm}$.

Tracings were read manually and blindly. Reading was repeated three months later to test reproducibility of analysis. Results were similar on both readings.

Analysis of myoelectrical activity in the six-channel tracings consisted of counting the number of spike bursts, measuring their respective duration, and evaluating their migration character in 15-minute periods of observation. The number of spike bursts was expressed in terms of average per channel. Duration of activity was calculated by summing duration of the individualized bursts in the six channels and expressing the average per channel in terms of percentage on each 15-minute period of observation. To evaluate migration character, the spike bursts were looked for on the six channels and the time lag between them was measured. Migration was considered to occur when time lags increased progressively from one tracing to at least three consecutive tracings, aborad or orad. Pressure waves were analyzed according to their number and percentage of time occupied by waves with an amplitude higher than $3 \mathrm{~mm} \mathrm{H}_{2} \mathrm{O}$. These were also expressed by periods of 15 minutes.

Statistical analysis of results was done using Student's $t$-test for paired samples. Values were expressed as mean \pm SD. This study was approved by the Medical Research Committee of the Centro Hospitalar de Coimbra, and informed consent was obtained from all patients.

\section{Types of Potentials and Pressure Waves}

Definitions concerning potentials used by Christensen et al. ${ }^{8}$ in in vitro studies and later used in human studies by Bueno et al. ${ }^{9}$ and Schang and Devroede ${ }^{10}$ were adopted in this work. Three types of spike bursts were considered: 1) MLSB; 2) LSB; 3) SSB. Pressure waves were not classified according to migration, because they were registered only in one tracing.

\section{RESULTS}

\section{Migrating Long Spike Bursts}

Migrating long spike bursts are migratory potentials with a conduction velocity that averaged $15.6 \mathrm{~mm}$ / second, a mean duration of $22.9 \pm 6.3$ seconds (mean $\pm \mathrm{SD}$ ), and an amplitude varying from 100 to $500 \mu \mathrm{V}$ (Figs. 2 and 3).

Eighty-two percent of these bursts of potentials propagated aborad, 11 percent orad, and 7 percent in both directions. They originated at any level of the bowel studied and migrated from there aborad or orad, sometimes to short distances (Fig. 3).

Aborad migration of MLSB was associated with pressure waves 99 percent of the time (Figs. 2 and 3). These potentials represented 25 percent of the recording time. The meal significantly increased duration of activity of these bursts of potential to 38 percent of recording time $(P<0.01)$.

\section{Long Spike Bursts}

Long spike bursts are stationary potentials with a mean duration of $17.2 \pm 10.4$ seconds (mean \pm SD) and an amplitude varying from 100 to $500 \mu \mathrm{V}$. These bursts of potentials were seen in one tracing alone or in any combination of the other six tracings without any migration tendency. When they occurred in the most distal channel (which was located at the level of the pressure channel), they were associated with pressure waves only 46 percent of the time.

\section{Short Spike Bursts}

These potentials were seen in a rhythmic fashion. Spike frequency ranged from 5 to $20 \mathrm{~Hz}$, and amplitude varied from 50 to $300 \mu \mathrm{V}$ (Figs. 2 and 4). Mean duration was $3.2 \pm 0.3$ seconds (mean \pm SD) before the meal and $3 \pm 0.65$ seconds (mean $\pm S D$ ) after it. Rhythm ranged from 6.1 to 13.6 (average, $9 \pm 1.7$ ) per minute (mean $\pm \mathrm{SD}$ ). It varied from period to period, even in the same tracing.

Shortest duration of the periods with rhythmic SSB was 1.4 minutes and the longest was 21 minutes. Only in 7 of 12 patients were rhythmic SSB observed. One 


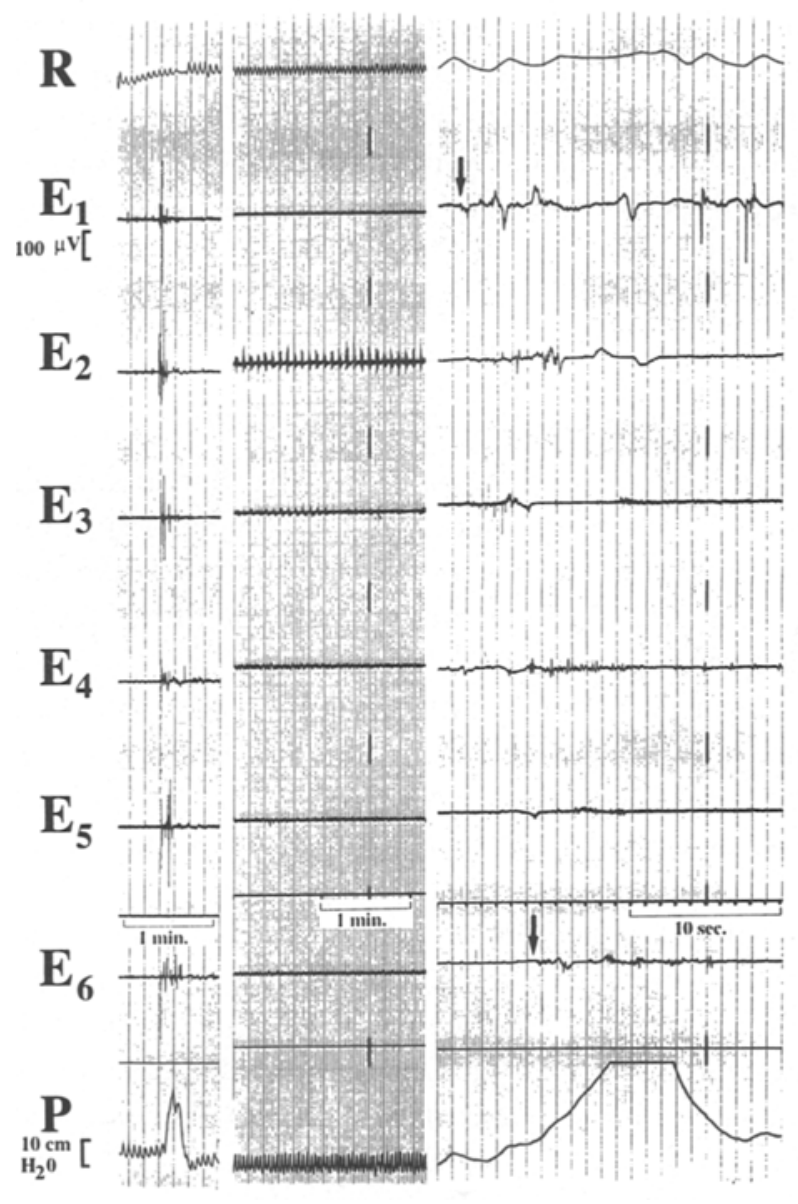

Figure 2. Three pieces of tracing showing on the strips of the left and right one migrating long spike burst at a velocity of $0.5 \mathrm{~mm} / \mathrm{second}$ and $5 \mathrm{~mm} / \mathrm{second}$, respectively. They are associated with pressure waves. The middle strip shows short spike bursts at $E_{2}$. These bursts did not migrate even to $5 \mathrm{~mm}$ below or above, as was the case in this strip. On this case, the electromyograph was reset to record from electrodes (6 and 9 of the probe), which were $0.5 \mathrm{~cm}$ apart from $E_{2}=7,8$, instead of $2.5 \mathrm{~cm}$ apart, as is usual. $R=$ respiration; $E_{1}-E_{6}=$ electrical channels; $\mathrm{P}=$ pressure channel.

of seven patients examined twice did not have rhythmic SSB in the first examination but showed them in the second. They appeared during fasting and after the meal but were more frequent before it. These bursts were also seen, sporadically, in a nonrhythmic fashion. In this case, all patients showed short spike bursts some time during the recording sessions.

SSB were never seen to migrate even to $0.5 \mathrm{~cm}$ above or below their point of origin (Fig. 2), and they never initiated pressure waves. On the other hand, spike bursts from the MMC, recorded by the same recording method, were always associated with highamplitude pressure waves (Fig. 4).

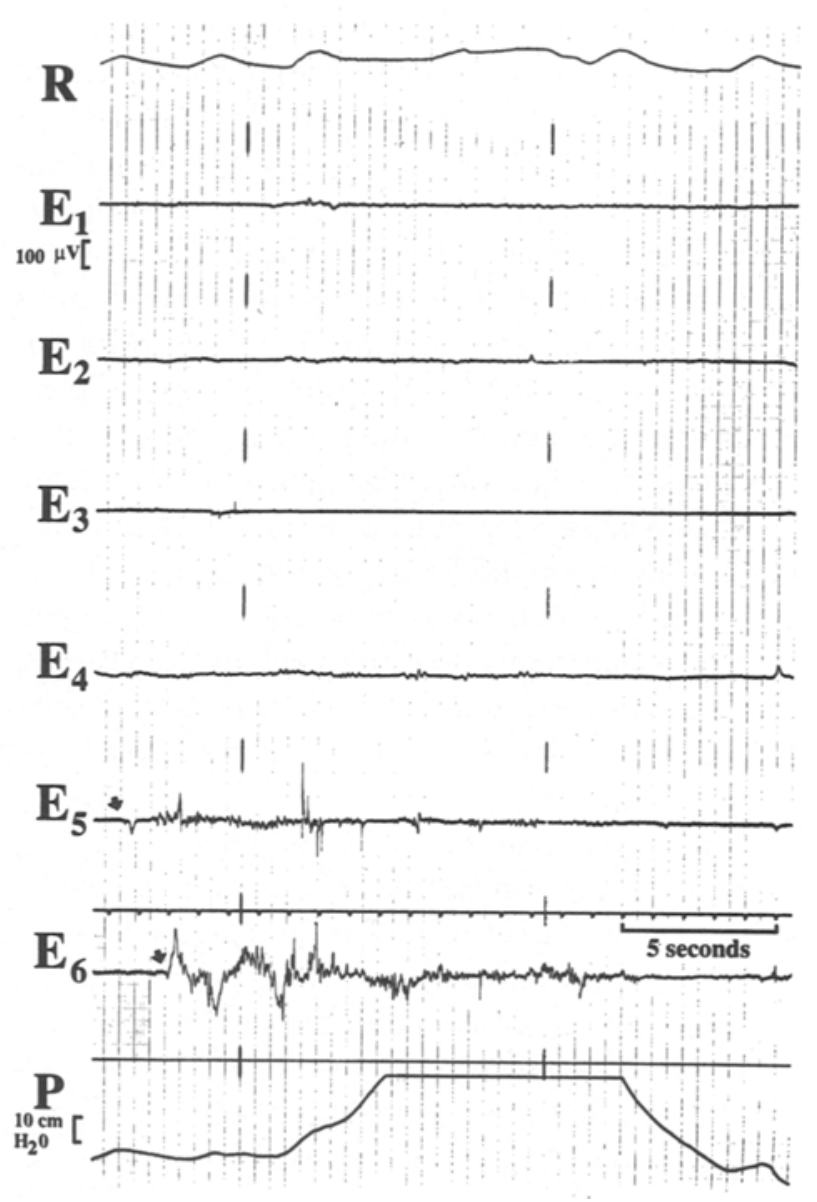

Figure 3. Migrating long spike burst, which started at $E_{5}$ and migrated to $E_{6}$. It propagated aborad to a short distance and originated one high-amplitude pressure wave. $R=$ respiration; $E_{1}-E_{6}=$ electrical channels; $P=$ pressure channel.

\section{Simultaneous Recording of Electromyography and Pressure}

There was a good relationship between number of MLSB on one hand and number of contraction waves on the other, i.e., 99 percent of the MLSB were associated with high-amplitude pressure waves (Fig. 2).

\section{Abolition of Electrical and Motor Activity by Fullness of the Bladder}

In two patients (whose desire to urinate was sustained) basal pressure started to rise and there was a complete abolition of the electrical spike activity and motor activity for more than 30 minutes. After micturition, there was a return to normal electrical and motor activity. These patients were not included in the study. 


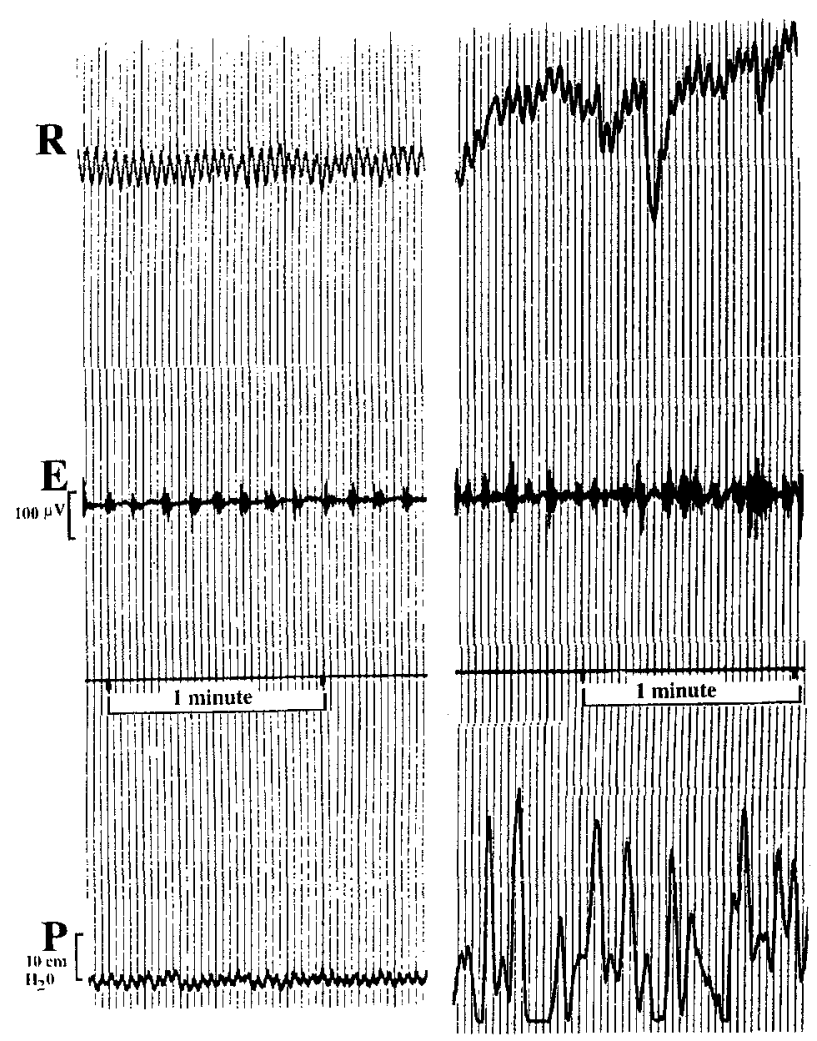

Figure 4. Left. Short spike bursts $(E)$, which are at the level of the balloon in the rectum. They did not originate pressure waves $(P)$. Right. One can see the electrical bursts of the migrating myoelectrical complex in the terminal ileum, which originated high-amplitude pressure waves in one to one relationship $(P)$. $R=$ respiration; $E=$ electrical channel $\left(E_{6}\right)$ on the probe, which is at the level of the balloon; $\mathbf{P}=$ pressure channel.

\section{Effect of Meal on Motility}

Total duration of activity and total number of long bursts of potentials (MLSB and LSB) were longer after the meal than before it. Time occupied by LSB and MLSB was 25 percent before the meal and 38.7 percent after it. The difference was significant $(P<0.01)$.

LSB and MLSB showed a peak on the postprandial period, which occurred 15 minutes after the end of the meal, but the difference between this value and mean values before the meal was not statistically significant. A statistically significant peak difference $(P<0.01)$ was also found 15 minutes after the meal, when MLSB alone were compared before and after the meal (Fig. 5). In 3 of 12 patients, LSB and MLSB were more frequent before the meal than after it.

Short spike bursts occupied 15.1 percent of the recording time before the meal and 9.6 percent after it. The difference was not significant. Figure 6 shows the number of SSB per 15-minute period before and

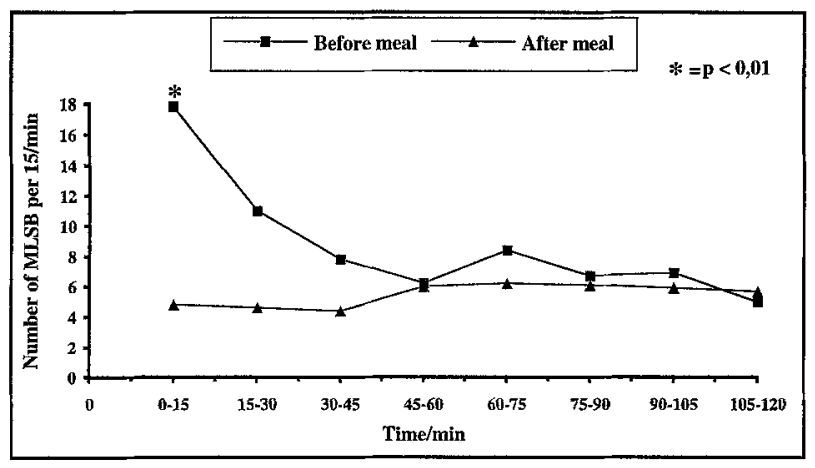

Figure 5. Number of migrating long spike bursts (MLSB) counted during 15-minute intervals before and after one $2,100-\mathrm{kJ}$ meal. Each square represents the mean number of spike bursts for 15-minute intervals in the 12 patients. Asterisk signals one significant value before the meal in relation to the average value after it $(\mathrm{N}=12)$.

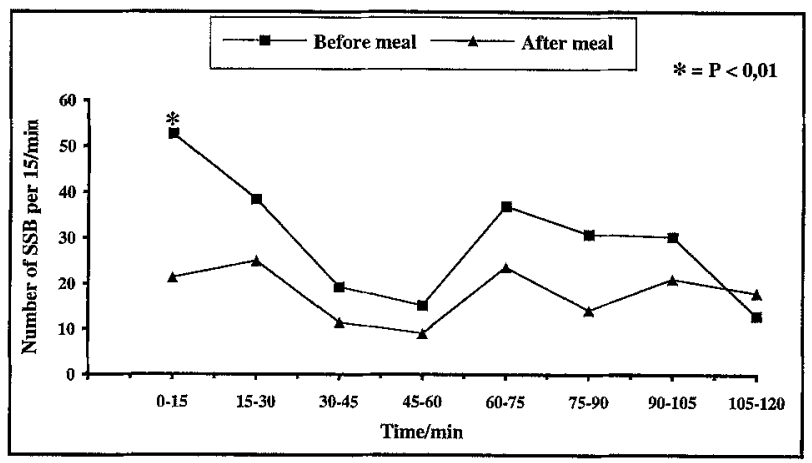

Figure 6. Number of short spike bursts (SSB) counted over 15-minute intervals before and after one 2,100-kJ meal. Each square represents mean number of spike bursts per 15-minute intervals in 12 patients. Asterisk signals one significant value before the meal in relation to the average value after it $(\mathrm{N}=12)$.

after the meal. Significant differences were seen in the initial 15 minutes of the examination $(P<0.01$; Fig. 6). Six individuals had higher numbers of SSB before the meal than after it, but the difference was not significant (Fig. 7).

\section{DISCUSSION}

In electromyography studies previously published, three types of bursts of action potentials of the colon have been described. These are the LSB, MLSB, and SSB reported by Christensen et al. ${ }^{8}$ and Bueno et al. ${ }^{9}$ Schang and Devroede ${ }^{10}$ used similar definitions (rhythmic spike potentials, sporadic nonpropagating and propagating potentials) and preferred to use the term propagating instead of migrating. On the classification reported by Sarna et al., ${ }^{13,23} \mathrm{SSB}$ corresponds to the discrete electrical response activity, LSB to the 

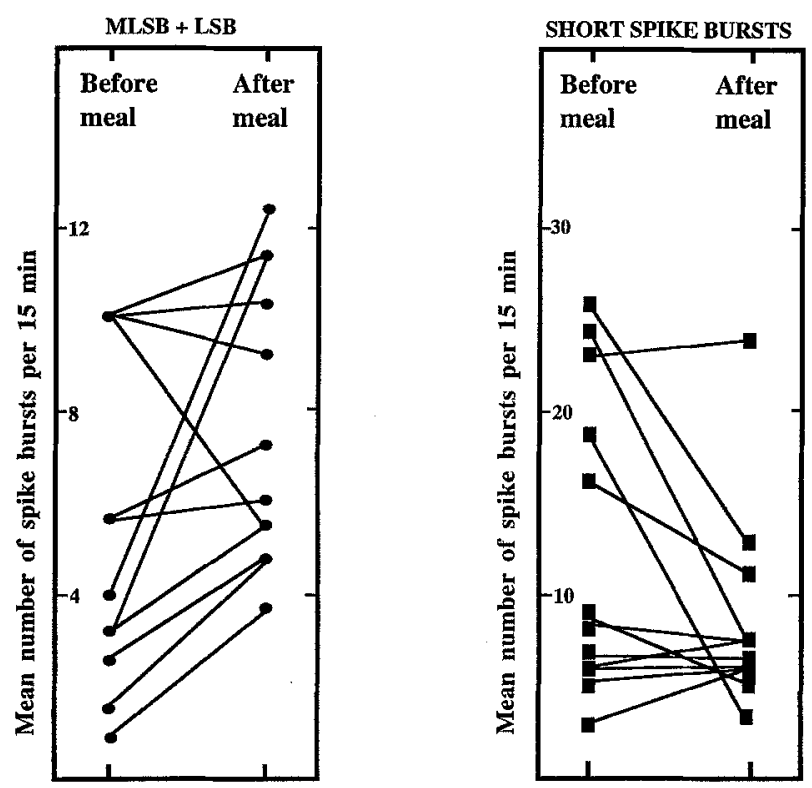

Figure 7. Diagram showing on the left the mean number of migrating long spike bursts (MLSB) plus long spike bursts (LSB) in each individual before and after the meal. Right. Mean number of short spike bursts in each individual before and after the meal. Each dot or square represents the mean number of bursts per 15 minutes $(\mathrm{N}=12)$.

continuous electrical response activity, and MLSB to contractile electrical complex.

Some authors have considered the SSB an electrical counterpart of the segmental pressure waves of the colon. ${ }^{9,}{ }^{10}$ By the method used in this study, no pressure waves related to SSB were seen. Sarna ${ }^{24}$ recorded wall contractions with strain gauges and considered them a counterpart of the SSB. In our study, SSB were never associated with intraluminal pressure waves, and this may suggest that wall contractions observed by Sarna do not have physiologic relevance, because they do not initiate intraluminal pressure waves. Segmental waves are easily recorded by miniballoons, and we have never seen SSB associated with them. SSB have a mean duration of three seconds and a mean rhythm of approximately nine per minute. This is not compatible with a one-to-one relationship with segmental waves in humans. Segmental waves are often nonrhythmic and have a mean duration of 25 seconds. Another factor against the relationship of SSB and segmental waves is that these waves were often present in patients who did not show SSB. Unlike colonic SSB, small-bowel rhythmic spike bursts, as part of the MMC, were always associated with high-amplitude intraluminal pressure waves recorded by the same method (Fig. 4). Medeiros and
Pontes $^{25}$ described a type of rhythmic long spike bursts with a duration of eight seconds after spontaneous or laxative-induced bowel irritation or after a MLSB similar in appearance to SSB. These spike bursts were always associated with pressure waves.

MLSB originated at any level of the bowel studied and migrated to short distances $(2,5 \mathrm{~cm})$ or longer, so they do not always start on proximal or mid colon as has been suggested. ${ }^{9,10,12,13,24}$ Perhaps some information regarding any one event may be lost when groups of electrodes are too separated.

Fullness of the bladder inhibited electrical and motor activity of the colon in two patients. This effect may be caused by sympathetic activation of the efferent fibers in hypogastric nerves as shown by Bouvier et $a .^{26}$ in the cat.

\section{CONCLUSIONS}

SSB in rectosigmoid are a different phenomena from MMC in the small bowel because they do not migrate, even to short distances $(1 \mathrm{~cm})$, they do not initiate pressure waves detected by a intraluminal mini-balloon, and they were seen either in the fasting or in the postprandial period. Origin of the SSB is still questionable. They may originate in localized pacemakers, which fire during a short period of time for some yet unknown reason. Their physiologic function is still unexplained, because no pressure waves, which could be originated by them, were detected by an intraluminal balloon.

\section{ACKNOWLEDGMENT}

The authors thank Dr. Francisco Alte da Veiga from the Centre for Computer Sciences for help with statistical analysis.

\section{REFERENCES}

1. Daniel EE, Berezin I. Interstitial cells of Cajal: are they major players in control of gastrointestinal motility? J Gastrointest Mot 1992;4:1-24.

2. Tamai T, Prosser CL. Differentiation of slow potentials and spikes in longitudinal muscle of cat intestine. Am J Physiol 1966;210:452-8.

3. Kobayashi M, Prosser CL, Nagai T. Electrical properties of intestinal muscle as measured intracellularly and extracellularly. Am J Physiol 1967;213:275-86.

4. Szurszewski JH, Code CF. Activity fronts of the canine small intestine. Gastroenterology 1968;54:1304.

5. Vantrappen G, Janssens J, Coremans G, Jian R. Gastrointestinal motility disorders. Dig Dis Sci 1986;31:5S-25S.

6. Christensen J, Anuras S, Arthur C. Influence of intrinsic 
nerves on electromyogram of cat colon in vitro. Am J Physiol 1978;3:E641-7.

7. Sarna SK. Giant migrating contractions and their myoelectric correlates in the small intestine. Am J Physiol 1987;253:G697-705.

8. Christensen J, Anuras S, Hauser RL. Migrating spike bursts and electrical slow waves in the Cat colon: effect of sectioning. Gastroenterology 1974;66:240-7.

9. Bueno L, Fioramonti J, Ruckebusch Y, Frexino J, Coulom P. Evaluation of colonic myoelectrical activity in health and functional disorders. Gut 1980;21:480-5.

10. Schang JC, Devroede G. Fasting and posprandial myoelectric spiking activity in the human sigmoid colon. Gastroenterology 1983;85:1048-53.

11. Huizinga JD, Daniel EE. Control of human colonic motor function. Dig Dis Sci 1986;31:864-77.

12. Sarna SK, Bardakjian BL, Waterfal WE, Lind JF. Human colonic electrical control activity (ECA). Gastroenterology 1980;78:1526-36.

13. Sarna SK, Waterfal WE, Bardakjian BL. Types of human colonic electrical activities recorded postoperatively. Gastroenterology 1981;81:61-70.

14. Dauchel J, Schang JC, Kachelhoffer J, Eloy RE, Grenier JF. Gastrointestinal myoelectric activity during the postoperative period in man. Digestion 1976;14:293-303.

15. Fleckenstein P. A probe for intraluminal recording of myoelectric activity from multiple sites in human small intestine. Scand J Gastroenterol 1978;13:767-70.

16. Fioramonti J, Bueno L, Frexinos J. Sonde endoluminale pour l'exploration electromyographique de la motricité colique chez l'homme. Gastroenterol Clin Biol 1980;4: $546-50$.
17. Bouvier M, Grimaud JC, Naudy B, Salducci J. Effects of morphine on electrical activity of the rectum in man. J Physiol 1987;388:153-61.

18. Wright SH, Snape WJ, Battle W, Cohen S, London RL. Effect of dietary components on gastrocolonic response. Am J Physiol 1980;238:G228-32.

19. Daniel EE, Chapman K. Electrical activity of the gastrointestinal tract as an indication of mechanical activity. Dig Dis Sci 1963;8:54-102.

20. Connell AM. The motility of the pelvic colon. 1, Motility in normals and in patients with asymptomatic duodenal ulcer. Gut 1961;2:175-86.

21. Connell AM, Rowlands EN. Wireless telemetering from the digestive tract. Gut 1960;1:266-72.

22. Ritchie JA, Ardran GM, Truelove SC. Motor activity of the sigmoid colon of humans: a combined study by intraluminal pressure recording and cinerradiography. Gastroenterology 1962;43:642-68.

23. Sarna S, Latimer P, Campbell D, Waterfall WE. Electrical and contractile activities of the human rectosigmoid. Gut 1982;23:698-705.

24. Sarna SK. Myoelectric correlates of colonic motor complexes and contractile activity. Am J Physiol 1986;250: G213-20.

25. Medeiros JA, Pontes FA. Electromyography and manometry of the pelvic colon-a contribution to the understanding of it's function. Eur $\mathrm{J}$ Gastroenterol Hepatol 1996;8:453-9.

26. Bouvier M, Grimaud JC, Naudy B, Abysique A. Effects of stimulation of vesical afferents on colonic motility in cats. Gastroenterology 1990;98:1148-54. 